\title{
Digital Photogrammetry: For Playing With Historical Architecture Anamorphisms and For Seeking Authorship Traces
}

\author{
Edemar Dias Xavier Junior ${ }^{1}$, Adriane Borda Almeida da Silva ${ }^{1}$, Janice de \\ Freitas Pires ${ }^{1}$ \\ ${ }^{1}$ Universidade Federal de Pelotas, Brasil \\ e1432@hotmail.com \\ adribord@hotmail.com \\ janicefpires@gmail.com
}

\begin{abstract}
The techniques of representation by digital photogrammetry and laser scanning make it possible to obtain accurate three-dimensional models and are necessary to support the production of documents about built heritage, a process that can trigger advances in knowledge concerning the represented object. Through these technologies, a study is carried out to generate information about two elements of the eclectic architecture of Pelotas, one of them, the half-dome of a Chapel, authored by José Isella, and the other, the skylight of a mansion, which still has unproven indicators regarding its authorship. An analysis of formal organization under a geometric approach whas used, to identify aspects as that cloud increase or refute personal doubt. The associative logic between the parts of the elements and the mastery in controlling the anamortic effects promoted by these elements increase the hypothesis that Isella is also responsible for the skylight design.
\end{abstract}

Keywords: Heritage Representation, José Isella, Anamorphisms, Digital Photogrammetry, Laser Scanning

\section{Introdução}

Este estudo partiu do interesse em avançar sobre o conhecimento do processo produtivo de projeto envolvido na arquitetura eclética erguida no final do século XIX, na cidade de Pelotas, no sul do Brasil. Em particular se debruça sobre uma curiosidade que paira em relação à autoria do projeto de uma edificação específica: o casarão de número 8 do entorno da Praça Coronel Pedro Osório, situado no centro histórico da cidade. Este casarão é reconhecido também 
como a Casa do Conselheiro. Esta edificação, de 1878, era assim chamada porque o responsável por sua construção e primeiro proprietário foi Francisco Antunes Maciel, herdeiro de um poder econômico e social de famílias influentes na cidade e que se tornou um líder político, tendo o ápice de sua trajetória como Conselheiro do Império. Este casarão hoje abriga o Museu do Doce, um museu de responsabilidade da Universidade Federal de Pelotas. Esta edificação tem sido tratada sistematicamente como objeto de estudo, sob diversas abordagens, desde o campo da Museologia, das Artes e, especialmente, da Arquitetura, por sua importância para a história da cidade. Faz parte de um conjunto de três casarões, um bem reconhecido pelo Instituto do Patrimônio Artístico e Histórico Nacional, IPHAN, sob a justificativa de ser um dos primeiros exemplares do estilo eclético do país.

Em trabalho anterior, Borda et al, 2015, a Casa do Conselheiro foi objeto para uma experimentação no campo da representação por meio de tecnologia de escaneamento 3D a laser, quando assim foi adquirida uma nuvem densa de pontos que permite a documentação e investigação precisas sobre as características formais deste patrimônio.

Existe a hipótese de que o autor do projeto deste Casarão seja o Arquiteto José Isella, responsável por outras obras na cidade. Esta hipótese encontrase registrada nos estudos de Arquitetura de Chevallier (2002), e mencionada em Santos (2007) e Leal (2019), estudos da área das Artes e da Museologia, respectivamente. Chevallier (2002) esteve focada na própria biografia de José Isella, sem, contudo, encontrar documentação para afirmar a autoria deste arquiteto relativo a tal projeto.

Uma das particularidades da arquitetura desta edificação está na provocação multissensorial advinda das ornamentações de fachadas e tetos em estuque, e em especial do elemento claraboia, central ao corpo principal do Casarão. Este elemento, impregnado de simbolismos, pode ser compreendido, em sua localização no todo do Casarão e em sua configuração formal, a partir da sequência de imagens da Figura 1. A associação das duas imagens da esquerda da figura permite situar a claraboia, a qual está representada seccionada e por um modelo digital da nuvem de pontos, obtida pelo processo de escaneamento 3D, referido anteriormente, desde o interior dos ambientes do Casarão. A terceira imagem, uma fotografia do elemento desde o exterior, facilita descrever a maneira como o projetista buscou matizar a cor da luz que incide no interior da edificação. Trata-se de uma estrutura poliédrica, em ferro e vidro, que muito se aproxima a uma superfície cônica, a qual permite, desde um ponto de vista interno, ver a cor do céu. Entretanto, há um cilindro, na base desta estrutura, constituído por um friso de vidros em tons de azul, invisível desde o interior, porém com a nítida função de produzir uma iluminação zenital de um dia com céu azul. A imagem da direita ilustra o efeito produzido por este coroamento. Ao se erguer a mirada, desde o centro do ambiente onde se situa esta claraboia, um olhar atento pode perceber a representação de um olho. Internamente, o tronco de cone que sustenta o elemento é revestido por uma superfície curva, em estuque, a qual auxilia na indução da percepção visual de 


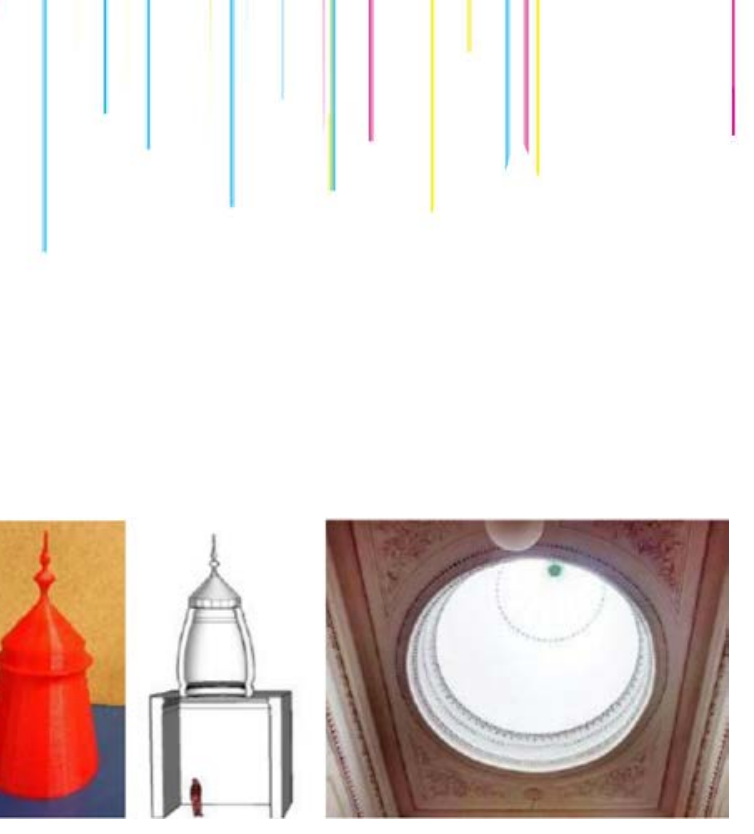

Figura 3. Representações da claraboia do Casarão 8: modelo físico/volumetria externa; seção perspectivada; fotografia. Fonte: Peronti et al, 2016.

É sobre esta habilidade de provocar percepções visuais específicas sob um determinado ponto de vista que se embasa esta investigação para reforçar ou refutar a hipótese da autoria de Isella sobre o Casarão 8.

Em Borda (2020), encontra-se destacado outro caso na arquitetura eclética pelotense que demonstra este mesmo tipo de habilidade do projetista para a construção de imagens, em uma edificação cuja obra foi inicializada quase no mesmo ano de conclusão do Casarão 8. Trata-se do caso da Capela da Santa Casa de Misericórdia de Pelotas, uma obra com a autoria comprovadamente atribuída a José Isella.

A demonstração desta habilidade refere-se a uma imagem específica que é oferecida ao espectador ao acessar a Capela, pela porta principal. De acordo com Chevallier (2002), esta Capela foi edificada entre os anos de 1877 e 1884 e, como pode ser compreendida pela fotografia aérea, à esquerda da Figura 4, está posicionada como elemento central da fachada principal do complexo de todo o hospital. O desenho de José Isella, apresentado na segunda imagem da mesma figura, propõe um vão aberto, interpretando-se como um convite para adentrar e contemplar a imagem criada para o interior da Capela. Por meio do desenho em planta baixa, pode-se observar que o altar está coberto por uma meia cúpula, a qual, como mostra a fotografia na sequência, é percebida como uma cúpula inteira, propositalmente, sob o ponto de vista de quem acessa a capela.
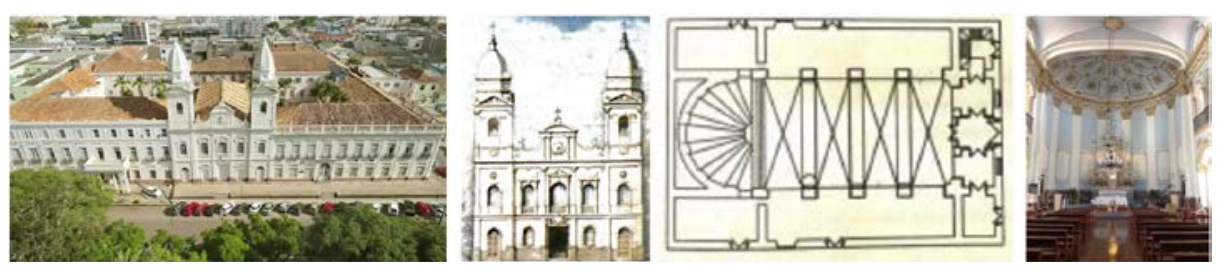

Figura 4. Fachada da Santa Casa de Misericórdia, Desenho da fachada e planta baixa ao centro e meia cúpula vista da entrada da Capela. Fonte: Chevallier, 2002.

Há um conjunto de elementos construtivos que estão configurados para reforçar este efeito anamórfico e enganar o olho do espectador. 
Entende-se assim que este controle formal, apoiado em um conhecimento próprio da perspectiva, identificado em poucas obras desta arquitetura pelotense do final do século XIX, possa ser outro indício para reforçar a hipótese aqui abordada.

Este controle preciso, para a geração de efeitos anamórficos, certamente Isella traz de sua formação, como arquiteto italiano, apoiada nos estudos dos tratadistas do século XVI. De acordo com Cabezos et al (2014), os primeiros tratados em abordar a anamorfose são os de Vignola, de 1562, e de Barbaro, de 1568. Tais efeitos são estratégias exploradas para estabelecer uma linguagem arquitetônica, tanto sob um teor metafísico como de divertimento (Alves, 2016).

Para compreender a maneira de organização formal envolvida em ambos os casos, do efeito da claraboia do Casarão 8 e da meia-cúpula da Capela da Santa Casa, buscou-se o apoio nos recursos digitais de representação, especialmente os que garantem maior precisão como são as tecnologias de escaneamento 3D, já disponível para o estudo do primeiro caso, e a fotogrametria digital, aqui utilizada para o estudo do segundo caso. A obtenção de modelos por estas tecnologias facilitam a manipulação virtual dos elementos envolvidos para extrair os parâmetros geométricos utilizados, tratase assim de um estudo de abordagem geométrica.

Se aposta na comparação de uma representação precisa e interpretativa destes elementos, por meios digitais, para identificar indícios, geométricos, que possam reforçar ou refutar a autoria de Isella ao projeto do Casarão. $O$ interesse está também em constituir representações que permitam traduzir os conhecimentos gerados a uma linguagem acessível de difusão. Apoia-se em Piaget, para justificar a importância de gerar representações que possam ser manipuladas em sua tridimensionalidade e, com isto, ativar a tomada de consciência sobre a intenção projetual que atribuiu às arquiteturas abordadas esta dimensão simbólica, estética e emocional.

\section{Metodologia}

O estudo contemplou uma breve revisão bibliográfica e documental sobre José Isella e suas obras de arquitetura, apoiando-se especialmente em Chevallier (2002) e nos estudos do campo da Museologia para compreender as circunstâncias do momento construtivo da Casa do Conselheiro e as razões das dúvidas autorais, investigadas por Leal (2019).

O desenvolvimento do tema foi impulsionado por atividades de disciplinas de mestrado, junto ao Programa de Pós-graduação em Arquitetura e Urbanismo (PROGRAU) da UFPel. As disciplinas envolvidas foram: Representação Gráfica e Digital para Arquitetura e Urbanismo (2019/02), a qual subsidiou o uso de conceitos de organização formal, desde as análises de relações proporcionais ao conceito de anamorfismo, para a compreensão de procedimentos de modelagem geométrica e visual, sobre a representação 
da forma e da aparência da arquitetura; Análise e Representação de Geometrias Complexas da Arquitetura Contemporânea (2020/02), a qual subsidiou a compreensão dos tipos de superfícies curvas envolvidas nos projetos, por meio da análise e implementação de esquemas em desenho paramétrico; Fundamentos para a docência em Representação Gráfica e Digital (2021/01), a qual subsidiou com fundamentos didáticos associados ao uso do conceito de jogos. Por outra parte, teve o apoio em uma parceria com o Departamento de Expressão Gráfica da UNIZAR, pelo acesso aos materiais didáticos disponibilizados junto a um sistema formativo, na modalidade remota, em fotogrametria digital por meio da disciplina dirigida à graduação, Representação do Patrimônio. Esta oportunidade promoveu o aperfeiçoamento no emprego de tais tecnologias.

Cada uma das atividades foi sistematizada para constituir elementos teóricos e tecnológicos para compor uma narrativa para o desenvolvimento de um jogo digital, por meio do uso de plataformas de jogos para constituir um ambiente digital interativo tridimensional, de acesso livre e gratuito. Teve-se em conta o interesse de disponibilização deste jogo nos sites do próprio Museu do Doce (sediado no Casarão) e do Museu da Santa Casa. Traduzir este estudo em um jogo digital tem como objetivo oportunizar a construção de conhecimento sobre tais arquiteturas de maneira coletiva, na expectativa de que com a difusão e acesso possam advir de uma interação dialógica com a sociedade em geral, elementos que contribuam para incrementar as informações sobre a questão aqui estudada. Além disto, esta difusão permite evidenciar as especificidades técnicas da arquitetura de Isella, sob esta abordagem geométrica, de controle preciso dos efeitos da perspectiva, detalhes que muitas vezes podem passar despercebidos pelos olhares leigos ou até mesmo pelos mais especializados no campo da arquitetura.

O uso de uma nuvem de pontos obtida por escaneamento 3D preexistente foi aplicado para a obtenção do modelo tridimensional da claraboia do Casarão 8. Embora a nuvem estivesse disponível, os dados do escaneamento utilizados ainda não tinham sido tratados. Foi necessária a execução de um processo de limpeza, segmentação da área de interesse, para a obtenção do modelo tridimensional utilizado para análise e para a execução do que se configurou como um jogo para a interação com o modelo. Já para a meia cúpula da Capela da Santa Casa de Pelotas, foi necessário executar um levantamento fotográfico para a produção de uma nuvem por fotogrametria digital para a obtenção do modelo tridimensional do elemento. Ambos os modelos foram configurados no formato OBJ (passível de ser utilizado em plataformas de jogos digitais).

Representações técnicas e interativas, para a compreensão dos parâmetros geométricos, foram utilizadas para o estudo de cada elemento. As análises geométricas foram realizadas sobre as representações em projeções ortogonais, quanto às questões métricas e relacionais, utilizando-se de comparações com padrões proporcionais clássicos, reincidentes na produção destes exemplares da arquitetura eclética historicista pelotense. O estudo das 
Destaca-se que, como se trata de uma nuvem de pontos composta por mais de um escaneamento, foi refeito o cálculo das normais, para que fossem corrigidas e, desta maneira nenhuma parte da nuvem resultasse em uma malha contendo faces invertidas. Com esses processos a Triangulated Irregular Network (TIN) ou malha triangular irregular gerada foi também otimizada, o que resultou em um modelo de superfície mais uniforme e menos denso do que teria sido sem a realização dos procedimentos citados. Este modelo de superfície foi gerado no formato *.obj.

Entretanto, mesmo com tais otimizações, este modelo de superfície ainda apresenta uma TIN muito densa, com um elevado número de triângulos, o que não é adequado para a manipulação em tempo real. O arquivo resultante desse processo possui 992753 vértices, 1979238 faces e 168.886KB. Com o propósito de reduzir, foi utilizado o software Instant Meshes o qual auxilia na simplificação da TIN, tratando de avaliar as normais de triângulos adjacentes para fusioná-los quando estas são praticamente correspondentes. Com este procedimento o arquivo do modelo passou para 69245 vértices, 137924 faces e 12.154 MB. Trata-se ainda de um arquivo extremamente pesado para o desenvolvimento de modelos para jogos digitais, frente às recomendações usuais (Unreal, 2021). Ainda assim é bem menos que os 50MB que o repositório do sketchfab permite de carga e que será utilizado posteriormente no desenvolvimento do jogo. Outra questão, a ser considerada para relativizar, é que o modelo irá ser instanciado apenas uma vez na máquina do usuário e o jogo ficará hospedado na web, e esses valores não apresentam atualmente grande problema frente à qualidade do modelo gerado e o desejo por parte dos desenvolvedores de que se manipule um elemento derivado de uma nuvem de pontos. O modelo gerado está disponível para ser manipulado de maneira aberta em <https://skfb.ly/oo998>.

A análise feita sobre a seção e a projeção ortogonal do modelo gerado pela nuvem de pontos permitiu identificar que a superfície interna, utilizada no elemento do Casarão 8, está configurada por um elipsoide alongado, seccionado nas extremidades, conforme mostra a Figura 6.
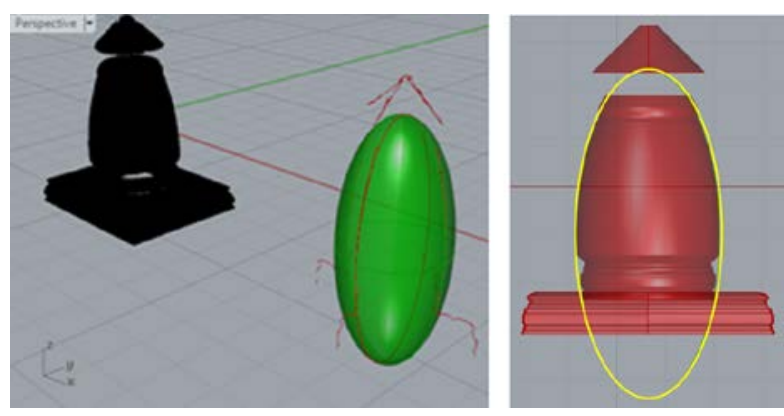

Figura 6. Identificação de um elipsoide alongado para configurar o elemento da claraboia. Fonte: Autores, 2021 

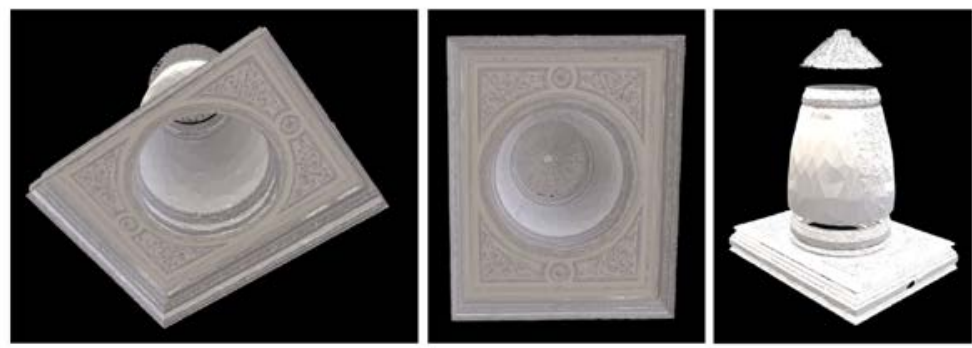

Figura 9. Modelo digital interativo do elemento claraboia. Fonte: autores, 2021

A Figura 10 ilustra a página provisória de acesso que está em fase de desenvolvimento do design. À esquerda tem-se o modelo interativo e à direita uma coluna prevista para a exposição das questões provocativas para motivar a manipulação do modelo associada ao conhecimento construído. A ideia é promover um processo dialógico com a sociedade e coletar dados sobre as percepções e informações que possam auxiliar para a elucidação do problema tratado e compartilhar os saberes arquitetônicos aqui explicitados sobre a obra do arquiteto José Isella ou de outros projetistas que atuaram neste cenário do século XIX na cidade de Pelotas. As questões enfatizarão as estratégias anamórficas e das lógicas associativas entre as partes dos elementos estudados para que haja o empoderamento do jogador para que também possa discutir e elaborar hipóteses quanto à autoria do projeto da claraboia.

\section{Uma obra de José Isella:}

\section{Capela da Santa Casa de Misericórdia de Pelotas}
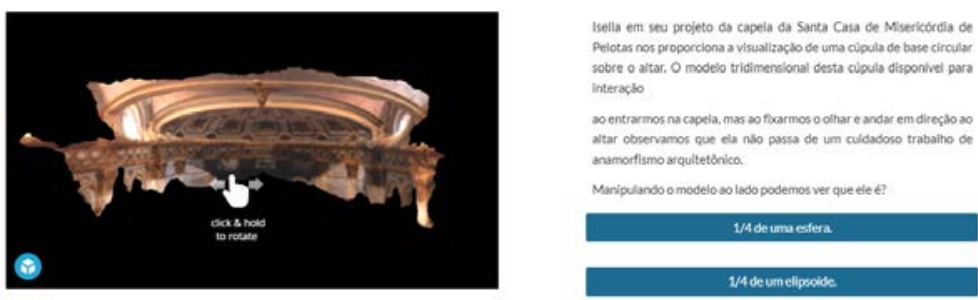

Figura 10. Interface provisória para o jogo digital. Fonte: autores, 2021. 
Chevallier, C. M. (2002). Vida e obra de José Isella: arquitetura em Pelotas na segunda metade do século XIX. (Mundial, Ed.) Mundial.

Leal, N.(2019) A trajetória de uma construção patrimonial: a tradição doceira de Pelotas e antiga Pelotas na constituição do Museu do Doce da Universidade Federal de Pelotas. 2019. 291 f. Tese (Doutorado em Memória Social e Patrimônio Cultural) PPG em Memória Social e Patrimônio Cultural. ICH, UFPel, Pelotas.

Peres, R. M. (2008). Legado da tecnologia construtiva de imigrantes italianos ao patrimônio arquitetônico de pelotas. Ph.D. dissertation, UFRS.

Peronti, G., Veiga, M.; Borda, A. (2016). A extensão da percepção: uma experiência com a produção de modelos táteis para descrever a ambiência gerada pela claraboia do Casarão 8, Pelotas, RS In: III Congresso de Extensão e Cultura/Tecnologia e Produção. Pelotas: Editora da UFPel. v.7. p.48 - 51

Piaget, J.(2013). Psicologia da inteligência. Rio de Janeiro: Vozes. (Publicada originalmente em 1956).

Rezende, W. d. (2016). Do Analógico ao Digital: a evolução das Técnicas de Documentação do Ambiente Construido. (Paco, Ed.) Paco. Fonte: https://www.ebook.de/de/product/31800553/wagner_souza_de_rezende_do_anal ogico_ao_digital.html

Santos, C. A.(2007) Ecletismo na fronteira meridional do Brasil: 1870-1931. Tese (Doutorado em Arquitetura e Urbanismo) Universidade Federal da Bahia.

Unreal Engine. Portal de aprendizagem para desenvolvimento de jogos da Unreal Engine, acessado em 01/07/2021, disponível em: https://www.unrealengine.com/en-US/onlinelearning-courses

Zambrano, L.(2015). El centro histórico de la ciudad de Pelotas evolución urbana y gestión actual. Tesis (Programa de Doctorado y Diploma de Estudios Avanzados en Historia del Arte y Gestión Cultural en el Mundo Hispánico) Universidad Pablo de Olavide, Sevilla, España. 